\title{
RUNNING TO SAFETY: ANALYSIS OF DISASTER SUSCEPTIBILITY OF NEIGHBORHOODS AND PROXIMITY OF SAFETY FACILITIES IN SILAY CITY, PHILIPPINES
}

\author{
C. L. Patiño ${ }^{\text {a, } * \text { N. A. Saripada }}{ }^{a}$, R. D. Olavides ${ }^{a}$, J. Sinogaya ${ }^{b}$ \\ ${ }^{a}$ University of the Philippines Cebu Phil-LiDAR 1, Lahug, Cebu City, 6000, Philippines - clpatino@up.edu.ph, (nashsaripada.up, \\ rdolavides)@gmail.com \\ b Program for Environmental Studies, University of the Philippines Cebu, Lahug, Cebu City, Philippines - jrsinogaya1 @ up.edu.ph
}

Commission VIII, WG VIII/1

KEY WORDS: Hazards, Building Extraction, Flooding, LiDAR, Disaster Management

\begin{abstract}
:
Going on foot is the most viable option when emergency responders fail to show up in disaster zones at the quickest and most reasonable time. In the Philippines, the efficacy of disaster management offices is hampered by factors such as, but not limited to, lack of equipment and personnel, distance, and/or poor road networks and traffic systems. In several instances, emergency response times exceed acceptable norms. This study explores the hazard susceptibility, particularly to fire, flood, and landslides, of neighborhoods vis-à-vis their proximity to safety facilities in Silay City, Philippines. Imbang River exposes communities in the city to flooding while the mountainous terrain makes the city landslide prone. Building extraction was done to get the possible human settlements in the city. The building structures were extracted through image processing using a ruleset-based approach in the process of segmentation and classification of LiDAR derivatives and ortho-photos. Neighborhoods were then identified whether they have low to high susceptibility to disaster risks in terms of floods and landslides based on the hazards maps obtained from the Philippines' Mines and Geosciences Bureau (MGB). Service area analyses were performed to determine the safety facilities available to different neighborhoods at varying running times. Locations which are inaccessible or are difficult to run to because of distance and corresponding hazards were determined. Recommendations are given in the form of infrastructure installation, relocation of facilities, safety equipment and vehicle procurement, and policy changes for specific areas in Silay City.
\end{abstract}

\section{INTRODUCTION}

\subsection{Background}

Natural disasters like typhoons, floods, landslides, and other calamities have battered the Philippines in the recent years. The United Nations have tagged the country as the $2^{\text {nd }}$ most vulnerable country to natural disasters in the former's World Risk Report in 2014. Despite risks posed by natural disasters, the country's disaster management offices are hampered by factors such as lack of equipment, personnel, and road infrastructure.

The Department of Interior and Local Government has aimed for a six-minute response time (Cervantes, 2014) for the Bureau of Fire Protection, however, the target is usually exceeded due to the aforementioned problems.

With the dilemma of lacking facilities, particularly rescue vehicles, during emergency situations, this study aims to assess the on-foot accessibility of safety facilities (such as hospitals or health centers, rescue and disaster management offices, and evacuation centers).

On-foot accessibility is considered here as a facility's proximity allowing a potential disaster victim to reach such facility when the individual's available option is to evacuate on foot -either running or walking.

\subsection{Study Area}

The city of Silay is situated in Negros island in the western section of the Philippines. Based on the 2010 census by the Philippine Statistics Authority, Silay City has a population of 120,999 .

The city is considered among the areas with "high vulnerability" to flooding by the Negros Occidental Provincial Environment and Management Office (PNA, 2014) while its mountainous eastern section is also exposed to possible landslides. The city also has large swathes of high density residential areas which are susceptible to fire especially during the months of March to May when temperature exceeds 38 degrees Celsius.

For this study, the scope is on the flood plain of Imbang river basin in Silay City which covers a land area of 144.762 square kilometers.

\section{METHODOLOGY}

\subsection{Data}

Data used in this study include digital elevation models (DEMs), ortho-photos, road network shapefiles, and geohazard maps relevant to the Imbang flood plain in Silay City.

\footnotetext{
* Corresponding author
} 
DEMs and ortho-photos were obtained from the Philippine national hazard mapping project, Phil-LiDAR 1, which is a government-funded collaborative work between the country's universities including the University of the Philippines (UP) Diliman and UP Cebu for the Western Visayas Region. These DEMs and ortho-photos were processed to extract building footprints within the flood plain. The LiDAR data has a resolution of 1 meter and point density of 2-4 points per square meter while the ortho-photo has a resolution of 0.5 meter. Both datasets have Universal Transverse Mercator (UTM) Zone 51N projection.

Road network shapefiles were done via digitization of streets with the aid of digital surface models and ortho-photos of the city.

Geohazard maps used in this study were retrieved from the Mines and Geosciences Bureau (MGB).

\subsection{Building extraction}

A procedure for building extraction was designed to automatically retrieve structures within the flood plain. This made use of the combination of LiDAR data and 3-band RGB ortho-photo.

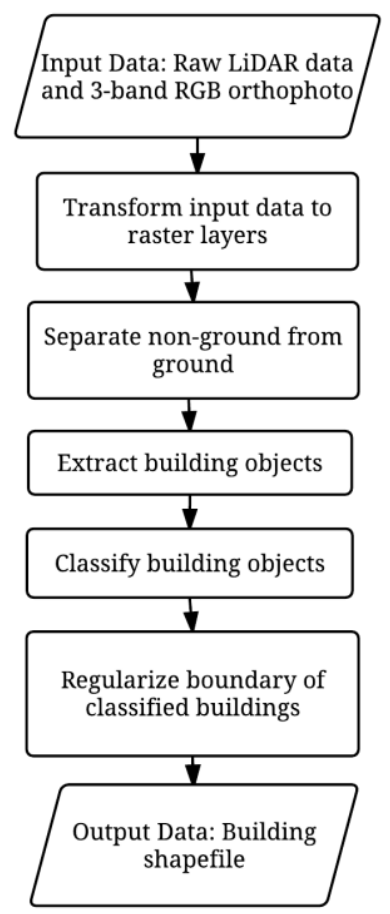

Figure 1. Building extraction workflow.

Figure 1 shows the workflow of the building extraction procedure. The method first transforms raw LiDAR data into raster layers such as Digital Surface Model (DSM), Digital Terrain Model (DTM), Canopy Height Model (CHM), Number of LiDAR pulse returns (NumRet) and LiDAR Intensity to distinguish buildings from other features using LASTools. The raster layers, along with a 3-band RGB orthophoto, are further processed by applying layer arithmetic and smoothening techniques. Using eCognition, non-ground objects are separated from ground using multi-threshold segmentation while buildings are extracted using multiresolution segmentation.
A rule-set based classification using different threshold values for different features from the data was used. Every segmented object was assigned to a class using different thresholds of slope, elevation, number of LiDAR pulse returns vegetation index, edge and spectral information.

A combination of the spectral properties of ortho-photo and topographical properties from the derived raster layers were used in the classification. Slope analysis has been one of the different approaches proposed to solve the problem of separating building class with other classes (Uzar and Yastikli, 2013). Moreover, several studies like Vosselman (2000), Wang et al. (2010), Uzar and Yastikli (2013) considered the slope information and integrated it into their methods for separating different classes.

The number of LiDAR pulse returns are also good discriminators of buildings from non-building class since buildings generally have a return value of 1 or less compared to other objects such as trees. The Normalized Digital Surface model (NDSM) is used because of the geometric description of the scene from the LiDAR data it provides (Weidner, n.d). Green vegetation index (GRVI) is one of the vegetation index often used in separating vegetation from non-vegetation. In this study, the datasets used in the classification process are the surface slope, number of LiDAR pulse return, the nDSM, GRVI, and the RGB orthographic photo.

\subsection{Hazard Exposure}

The geohazard maps from the MGB were used to determine using ArcMap the structures which are susceptible to landslides. Figure 2 shows the levels of susceptibility to flooding and landslides in the different areas of the Imbang flood plain in Silay City. The MGB (n.d.) categorizes areas with "active/recent landslides and tension cracks that would directly affect the community" and those "with steep slopes and drainages" as highly susceptible to landslide. Meanwhile, areas which may experience one meter flood height after several hours of heavy rains are considered as highly susceptible to flooding (colored red). Areas with less than one meter flood height during extended exposure to heavy rainfall are considered to have low to moderate susceptibility to flooding (colored pink). No area in the flood plain is highly susceptible to landslides. Georeferencing was done to align the landslide and flooding susceptibility maps with the DSM and other data.

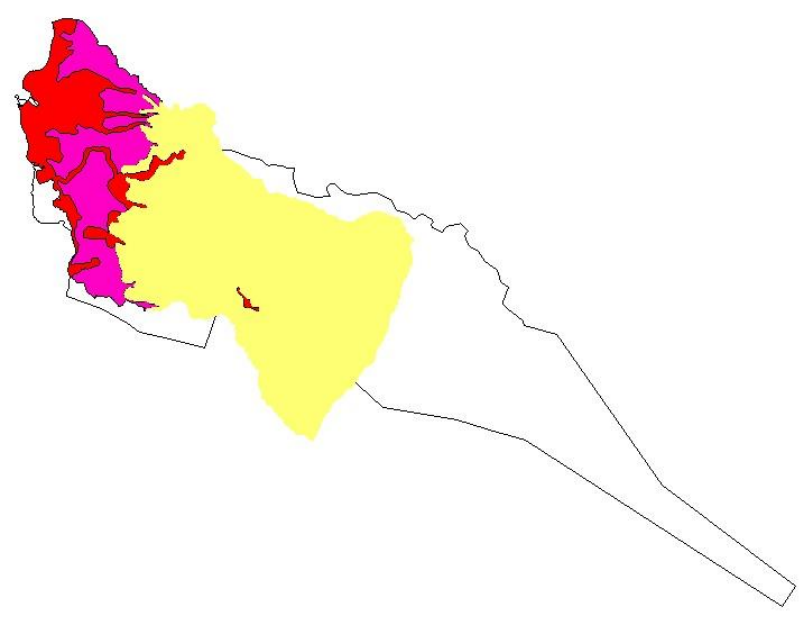

Figure 2. Flood and landslide susceptibility map. 


\subsection{Accessibility analyses}

The on-foot accessibility of the safety facilities in the flood plain was determined using the Buffer tool in ArcMap at $3 \mathrm{~km}$ radius. Meanwhile, the Service Area Analysis function was used to determine the accessibility of buildings in relation to their closest safety facility via the road network. Scenarios chosen were based on a six-minute target response time at 20,40 , and $80 \mathrm{kph}$.

\section{RESULTS AND DISCUSSION}

\subsection{Building extraction}

The floodplain was divided into ten (10) areas and was subjected to the feature extraction procedure. The performance of the method resulted to an average of $70.489 \%$ accuracy for extracting buildings. The accuracy results were derived by comparing the extracted building output with a manually digitized building shapefile. The total area of the extracted buildings is 3.161934 sq. $\mathrm{km}$. which covered $2.18 \%$ of the 144.762843 sq. km. floodplain. Figure 3 below shows the result of segmentation and regularization process of a sample area.

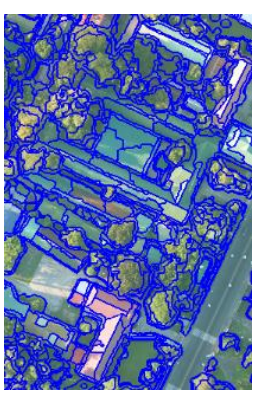

(a)

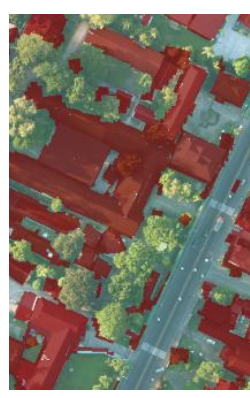

(b)

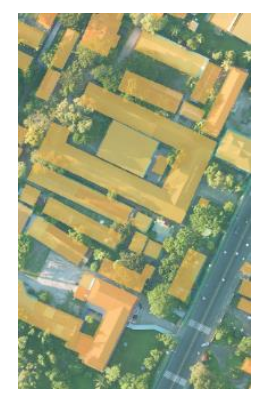

(c)
Figure 3. (a) Segmented buildings, the (b) regularized buildings and the (c) digitized buildings.

The proposed method was able to extract buildings which are not surrounded by other buildings. However, the proposed method did not perform well on areas where the building structures are dense and adjacent to each other which is usually the common residential setup in the Philippines. Accuracy assessment is detailed in Table 1 .

\begin{tabular}{|c|c|}
\hline Group \# & Accuracy \\
\hline 1 & 56.84 \\
\hline 2 & 75.6 \\
\hline 3 & 79.5 \\
\hline 4 & 75.37 \\
\hline 5 & 80.54 \\
\hline 6 & 74.24 \\
\hline 7 & 71.28 \\
\hline 8 & 58.62 \\
\hline 9 & 60.15 \\
\hline 10 & 72.75 \\
\hline AVERAGE & 70.489 \\
\hline
\end{tabular}

Table 1. Accuracy of each block group.
The method did not perform well in separating buildings which are very proximate to each other thereby affecting the regularization output of these buildings. In the regularization process, the classified buildings which have rugged edges have been straightened and reshaped into rectangular form.

However, due to the extracted adjacent buildings, its regularized form produced an unintended merging and overlapping of adjacent buildings. An example is shown in in Figure 4.

The polygons derived from the process were subsequently used in the determining the hazard exposure of structures in the Imbang flood plain.

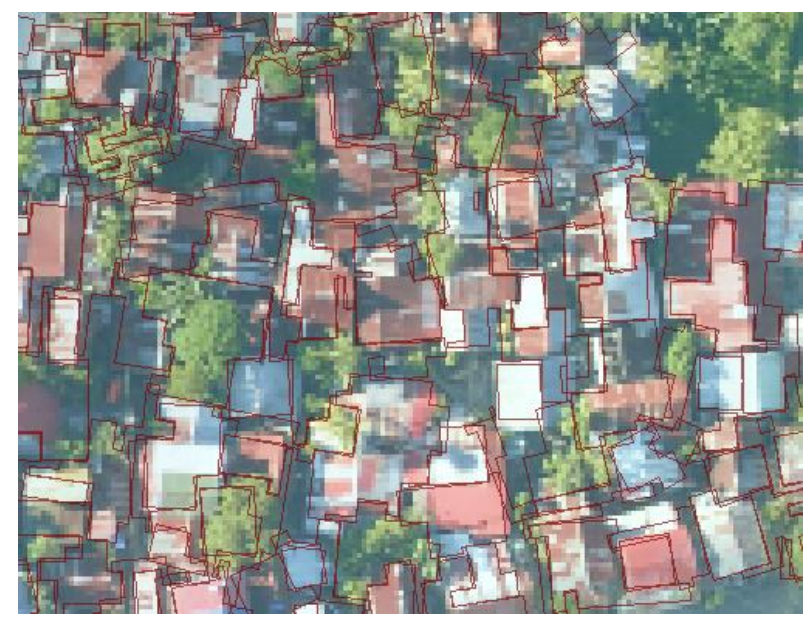

Figure 4. Regularized outline form of adjacent buildings-merged and overlapped.

\subsection{Hazard Exposure}

Among the 20,356 structures located in the flood plain, a total of $12,686(62.32 \%)$ features are in flood susceptible areas. Of these buildings, $4,750(23.33 \%)$ are within high flood susceptibility zones.

Figures 5 and 6 visualize a segment of the flood hazard exposure of the buildings in the flood plain.

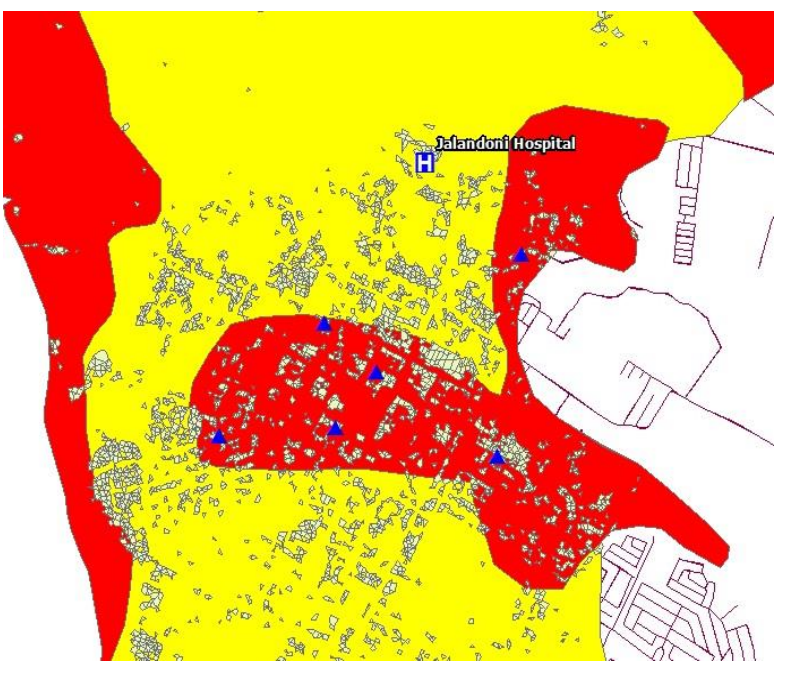

Figure 5. Exposure to low up to high flood susceptibility of buildings. 


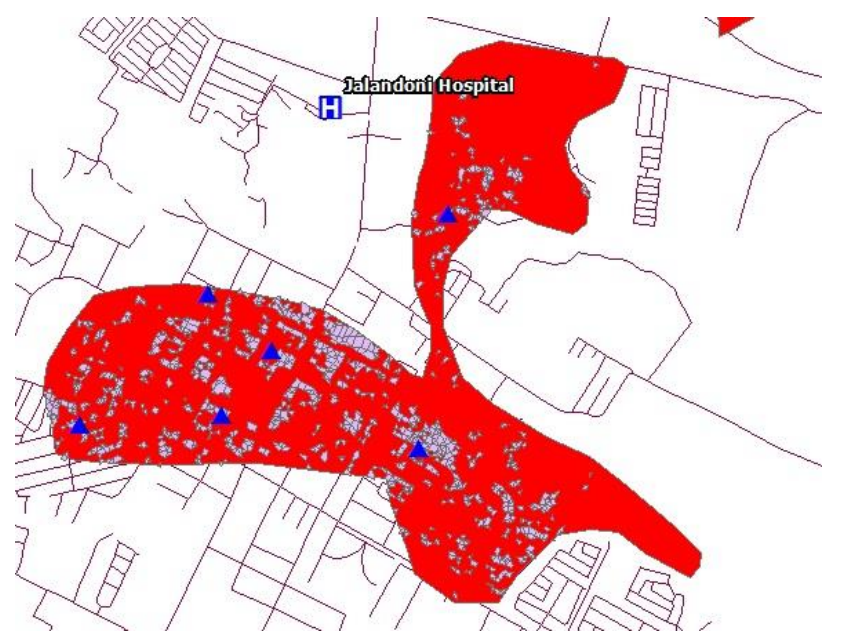

Figure 6. A map segment showing exposure to high flood susceptibility of buildings.

In the Philippines, schools serve as command centers and/or evacuation shelters during and after calamities. It was discovered that of the 65 schools, $32(49.23 \%)$ including the Teresita Jalandoni Provincial Hospital are with the low to high flood susceptibility areas. Thirteen of these schools are located in areas of high flood susceptibility as shown in Figure 7.

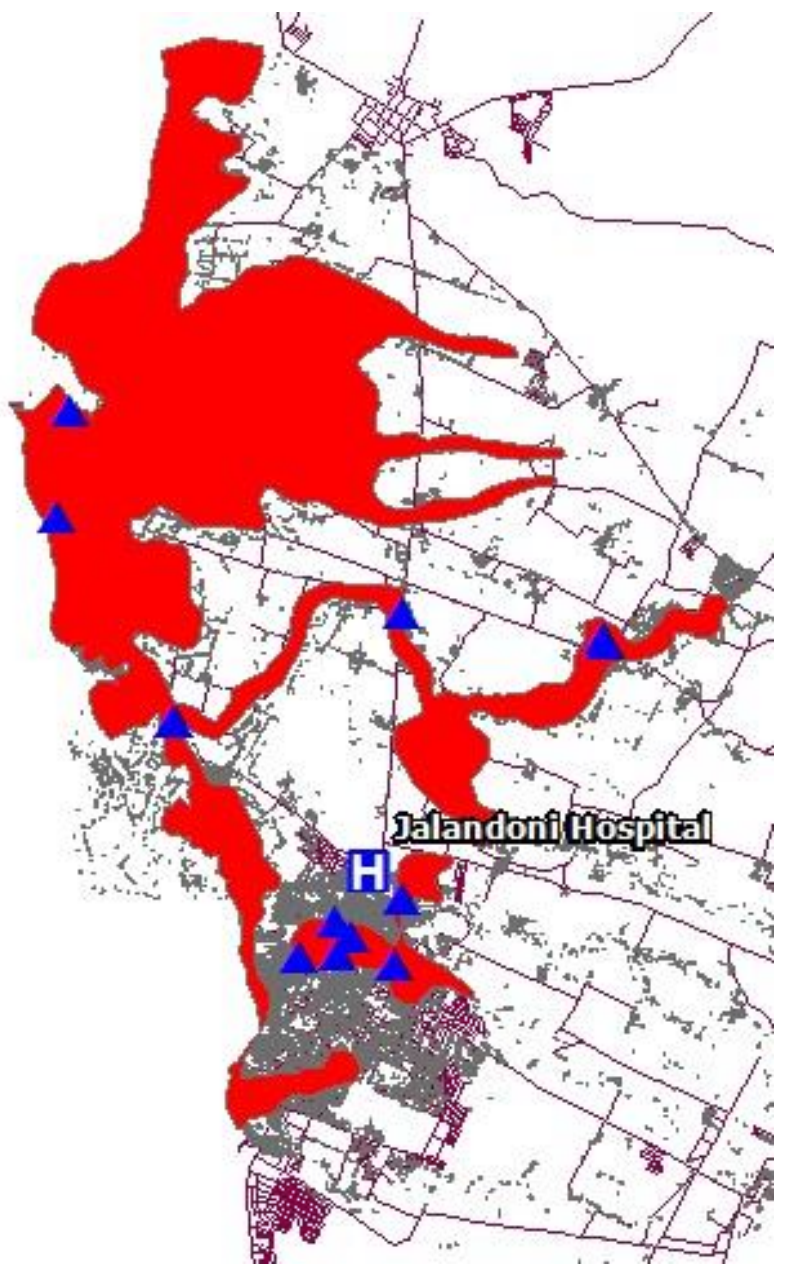

Figure 7. Map of safety facilities within the high flood susceptibility area.

\subsection{Accessibility Analyses}

On-foot accessibility was assessed using the Buffer tool in ArcMap and the results showed that there is generally a nearby safety facility reachable to schools within the radius of $3 \mathrm{~km}$. Figure 8 below illustrates this.

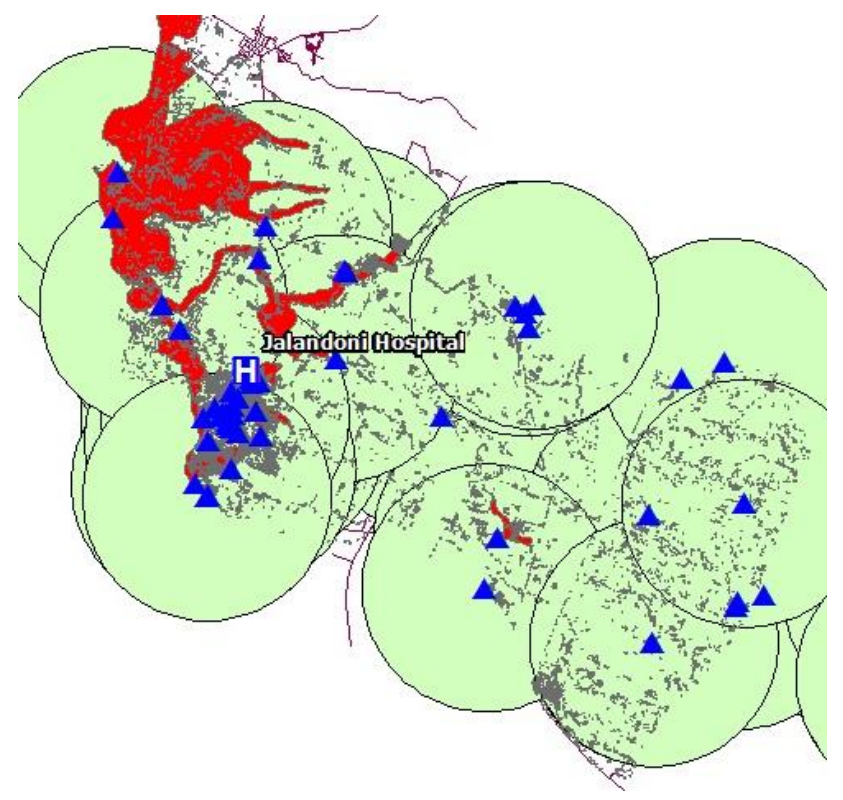

Figure 8 . Most buildings are within $3 \mathrm{~km}$ radius of a facility

Meanwhile, service area analyses yielded Figure 9 which shows that almost all of the buildings within the flood plain are accessible to emergency vehicles within a six-minute response time given the speeds of $20 \mathrm{kph}, 40 \mathrm{kph}$, and $80 \mathrm{kph}$. The result, however, discounts vehicular traffic conditions and narrow streets which hampers the speed of response. The time between a victim's call for help and the actual mobilization of emergency responders upon receipt of a distress call was not computed.

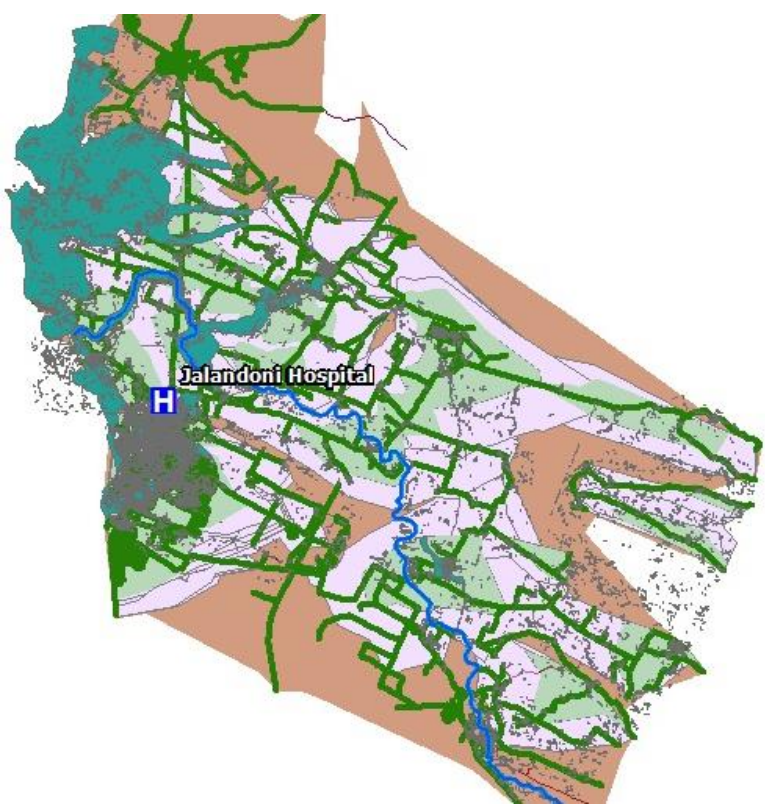

Figure 9. Service area analyses output. Brown areas need $80 \mathrm{kph}$ speed to reach the target 6-min response time. 
The service area analysis for the Silay Fire Department showed its strategic location as it is right in the middle of the high density residential area of the city. The buildings which may be covered within six minutes at varying speeds of $20 \mathrm{kph}, 40 \mathrm{kph}$, and $80 \mathrm{kph}$ total 11,731 or $57.63 \%$ of the structures within the flood plain. The result is shown in Figure 10.

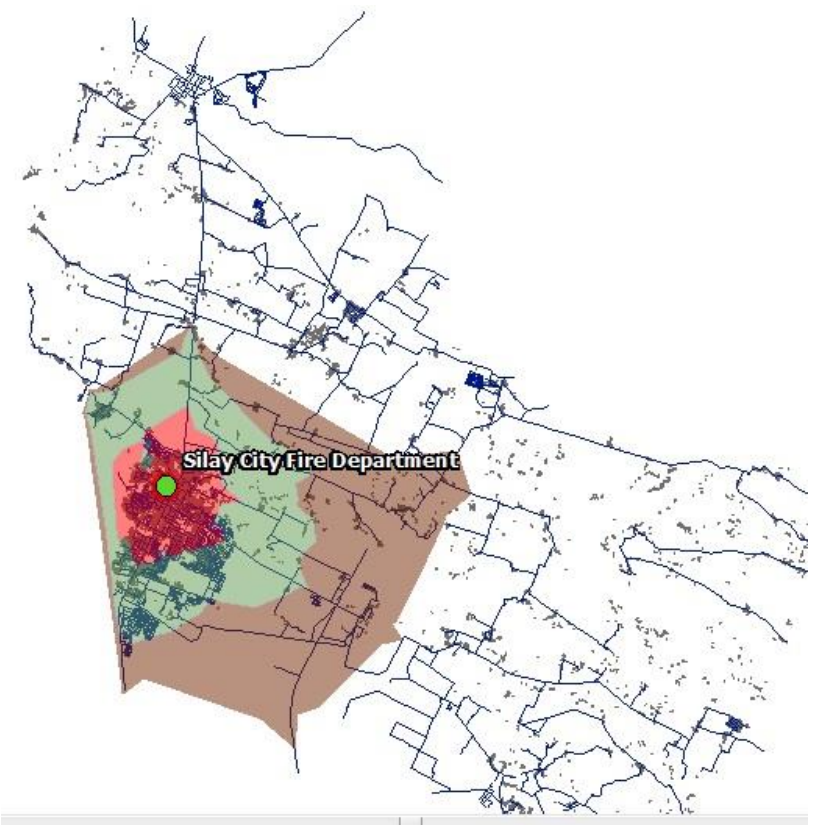

Figure 10. Service area network analysis for Silay City Fire Department

\section{CONCLUSIONS AND RECOMMENDATIONS}

The study was able to explore a process which automated the building extraction process. Using the output of the process, analyses of the different proximity relationships were done between existing safety facilities and the buildings located within the Imbang flood plain in Silay City, Philippines.

The emergency facilities remain inadequate as only one fire department serves the entire city of at least 20,000 built-up structures. However, through strategic placement of the fire department, it is able to serve more than half of its constituents at reasonable target response times. At the moment, the use of schools as safety facility allows for communities to have access to a shelter in times of calamity though this may be done on foot as the sheer population will overwhelm the deficient number of equipment for evacuation. Disaster management agencies must also look into the situation of schools as a number of these are also exposed to flood hazards.

\section{ACKNOWLEDGEMENTS}

This research is conducted by the University of the Philippines Cebu in collaboration with the University of the Philippines Diliman. This research is an output of the "Phil-LiDAR 1: Nationwide Hazard Mapping of the Philippines Using LiDAR: Western Visayas" project. We are grateful to the Department of Science and Technology (DOST) for the financial support. We are also thankful to the local governments of Negros Occidental and Silay City for their continuing assistance.

\section{REFERENCES}

Cervantes, D., DILG allots P4 B for new fire trucks (2014, Sep. 22), The Philippine Star.

ESRI, Service area analysis layer, http://pro.arcgis.com/en/proapp/help/analysis/networks/service-area-analysis-layer.htm.

Mines and Geosciences Bureau, Geohazard maps, http://www.mgb.gov.ph/

National Council on Strength and Fitness, Limits of human speed., https://www.ncsf.org/enew/articles/articles-limitsof humanspeed.aspx.

Philippine News Agency, (2014, December 8), Negros cities, towns prone to landslides, flooding, Panay News. Retrieved from http://panaynewsphilippines.com

Uzar, M. and Yastikli, N. 2013. Automatic building extraction using lidar and aerial photographs, http://www.scielo.br/pdf/bcg/v19n2/a01v19n2 (10 Jul. 2015)

Vosselman, G. 2000. Slope based filtering of laser altimetry data. In: IAPRS, Amsterdam, Vol. XXXIII

Wang S., Du W., Ai Zetian , Li G. 2010. Research on The Pile like Object Extraction Model in Mine Area Based on Multisource Remote Sensing Information.

Weidner. n.d. Digital Surface Models for Building Extraction In: Automatic Extraction of Man-Made Structures from Aerial and Space Images (II), Birkh“auser, Basel. 